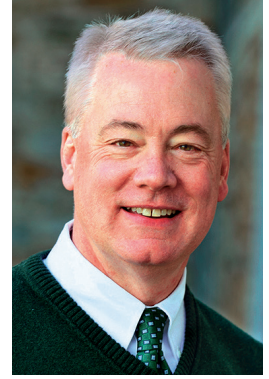

Mark Bailey

Hamilton College

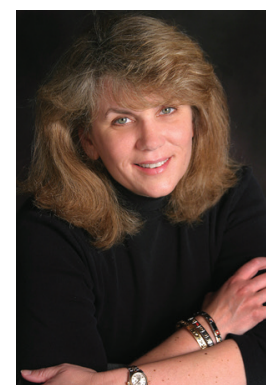

Laurie Smith King

College of the Holy Cross

\title{
EDITORS' MESSAGE
}

/ elcome to the December 2018 Inroads, a special issue that celebrates the $\bigvee$ 50th anniversary of the founding of the SIGCSE! This culminates work that began in March of 2017 when the SIGCSE Board asked us to celebrate the special interest group's semicentennial with a special edition of Inroads. We, along with our guest editor Jane Prey, have been working steadily since then to bring this issue to fruition. SIGCSE's history, current challenges, and possibilities for the future are explored and enticingly spiced with personal reflections from educators who cover the career spectrum, old-timers and first-timers alike. Jane's guest editor's message gives further details. Enjoy.

The familiar Inroads elements throughout the issue have a fiftieth anniversary twist. Notably, on the Back Page, John Barr offers a puzzle containing images from the last five decades (including ones of us!) that you must match to the correct decade. Check your work with the solution on page 108.

Barbara Boucher Owens describes the two prizes that ACM awards each year to computer science educators. Appropriate to this special issue, she has also gathered photos of past award winners. We thought this was so interesting that we asked her to run a pair of contests as well. You can find the URLs for the contests at the end of her article and on the Inroads website. These links will go live upon the arrival of this issue to your doorstep/inbox. Winners of the contests will receive free registrations to the SIGCSE Symposium this year. The deadline for submissions is before early registration for SIGCSE 2019 begins.

It seems just yesterday that we were welcoming Daniel Zingaro to our Editorial Advisory Board. Alas, Daniel is stepping down from the EAB in order to focus on achieving tenure. Daniel has provided many excellent reviews with key insights to help authors improve their work. We will miss Daniel on our Board and ask that you forward names on to us to fill his shoes!

Finally, this truly special issue could not have been accomplished without our guest editor, Jane Prey. From the outset, we knew we needed a guest editor for this issue, and we knew just whom to ask. In serving the SIGCSE community for well over 25 years, Jane knows everybody! Her special knack of twisting arms, cajoling, and sweetly nudging was just what we needed to get busy special-issue authors to write and submit their articles on time. Jane has done a beautiful job and we want to express our heartfelt thanks for taking on this project despite the pressures of professional duties, retirement, and 'grandmotherdom.' Jane, thank you from all of us - the readers, the authors, and, especially, Mark and Laurie. *

Mark Bailey and Laurie Smith King

Editors-in-Chief 